\title{
Spreadsheet Implementation for Optimization of Power Flow Network Problem: A Case Study of Kathmandu Valley
}

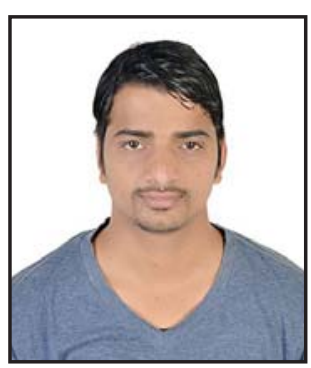

Sujan Acharya has been pursuing Master's degree in Energy System Planning \& Management and completed his bachelor's degree in Electrical Engineering from IOE, Pulchowk Campus. He is working as a Junior professor at Nepal Engineering College. His research interest includes demand side power management and fuel cell engineering.

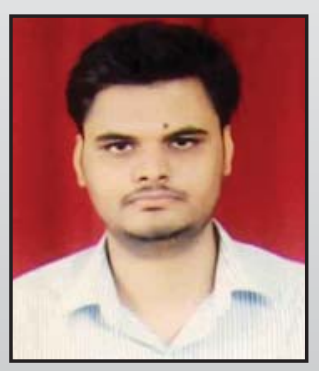

Anand Tewari has received his M.Tech degree in Power System Engineering from Lovely Professional University, India and B.Tech degree in Electrical Engineering from Uttar Pradesh Technical University, India. He is currently working as an Assistant Professor in Nepal Engineering College. His research interest includes FACTS technology and Artificial Intelligence.

\author{
Sujan Acharya ${ }^{1}$, Anand Tewari ${ }^{2}$ \\ Department of Electrical and Electronics, Nepal Engineering College \\ Changunaryan Bhaktapur, Nepal \\ 1'sujanbgl123@gmail.com, ${ }^{2}$ mail2anandtewari@gmail.com
}

\begin{abstract}
This paper is about the optimization of power loss in the power transmission network of the Kathmandu valley using spreadsheet modeling as an optimal power flow software. It is helpful for identifying the best path for the optimum power flow in dry as well as wet season. The available generating stations and substations taken as supply and demand nodes near Kathmandu valley are considered and the network is optimized as a transshipment flow problem. The main goal in this network flow model is to determine how much power should be allowed to flow across each transmission lines with minimal losses. In addition, optimization is performed considering the power import from India as well. Considering active power flow with a different scenario, and depending upon the load demand, the power system network is modeled in order to find out the best possible routes for efficient power flow with minimum loss.
\end{abstract}

Keywords : Optimization, electricity, optimal power flow, generators, transmission, network, spreadsheet modeling, energy imports.

\section{Introduction}

Nepal has a huge hydro-electrical potential expected to be at around $83000 \mathrm{MW}$ [1]. Currently, the power generation is about 1100 MW[2]. The Kathmandu valley needs $315 \mathrm{MW}$ peak power during the dry season and $275 \mathrm{MW}$ in wet season[3]. Kathmandu valley is currently served by a total of 14 grid substation and 13 generators have been utilized for the energy supply system. The accurate and reliable power flow has to be maintained for the stable and secure power system. The optimum power flow problems have a long history in its development. A generalized formulation of the economic dispatch problem including voltage and other operating constraints was introduced and later named the optimal power flow problem (OPF). The load flow problem in an electric power system is concerned with 
solving a set of static nonlinear equations describing the electric network performances [4].

Spreadsheet Modeling is one of the strong tools for optimization incorporated with a linear programming module [5]. Excel possesses a plug-in named Solver which is a powerful tool for constrained optimization and solving of non-linear equations. The solver can be used in power network calculations for both practical and educational purposes[6]it is often necessary to solve a large system of non-linear transcendent equations. Therefore, the program rou-tines are complex to develop, while specialized commercial soft-ware packages are expensive and not easily available. On the other hand, Microsoft Excel as a part of Microsoft Office software package is widely-spread in the world and rela-tively easily available. Excel possesses a plugin named Solver which is a powerful tool for constrained optimization and solving of non-linear equations. Solver can be used in power network calculations for both practical and educational purposes. Solver is also applicable to the other problems concerning electrical theory and practice (circuit theory, electromagnetics, etc.. Although there are numerous OPF algorithms to find the optimal solution, there is one common feature that permeates all these OPF tools, incorporation of a model of the power network.

Power flow studies are one of the most important aspects of power system planning and operation in terms of security and reliability[7]. The load flow gives us the sinusoidal steady state of the entire system-voltages, real and reactive power generated and absorbed and line losses. Power flow analysis is the backbone of power system analysis and design. They are necessary for planning, operation, economic scheduling and exchange of power between utilities.

Panda power is one of the tools based on Python aimed for optimization of balanced power systems[8]. The unified power flow controller (UPFC) is a FACTS device for the control of active and reactive power flow and can also be used for improving the quality of supply[9].

\section{Motivation}

Power flow analysis holds a key for planning, operation, economic scheduling and exchange of power between the utilities. Several optimization tools are available for the load flow. Some of the tools require high memory and take more time for solving each iteration as like Newton Raphson and Gauss-Seidel method. But, the spreadsheet simulation requires less computation time and less memory allocation. The power system needs dynamic control systems for reliable and secure operation. Therefore, this modeling can be one of the best optimization tools available for load flow.

\section{Literature Review}

Joram Schito it - Information Technology 2017; 59: 31-39 [10]: In planning transmission lines with the use of Geographic Information Systems, the use of the Least Cost Path (LCP) algorithm has been established while relevant criteria are modeled using Multi-Criteria Decision Analysis (MCDA). First results are promising since a stable algorithm has been developed that computes a cost surface, a Least Cost Corridor (LCC), an LCP, and the transmission towers' positions by simple additive weighting based on user's weights. The findings are integrated into a 3D Decision Support System which aims at facilitating the work of TL planners by realistic modeling and by reducing the approval process for new TL, that optimize a given quantity, possibly subjected to some restrictions on the allowed parameter ranges.

Zhigang Li, Member, IEEE, Jinyu Yu, and Q. H. Wu, Fellow, IEEE(2017)[11]: It proposes an approximate LPF method that considers active and reactive power and transmission losses simultaneously. A general LPF model considering tap changers and phase shifters are derived using the LTVM. An approximation for branch power loss is developed, and approximate complex branch flows considering power loss are formulated. The test results demonstrate that the proposed cold-start LPF-NIC and warm start LPF-IC models approximate the PF solution more accurately than several state-ofthe-art linear models in terms of the voltage magnitudes, branch load flows, and transmission power losses without additional computational burden.

Junchao Ma, Student Member, IEEE, Liqiang Yuan, Member, IEEE, Zhengming Zhao, Senior Member, and Fanbo He, Member, IEEE(2016)[12]: It is an OPF strategy for DC micro-grids based on hierarchical control is proposed to minimize the transmission loss in a generic DC micro-grid. Both converter loss and Ohmic line loss are taken into consideration. Simulation results show that the proposed method can realize both DC bus voltage regulation and OPF condition at the 
same time in both steady and dynamic situations.

\section{B. Hayes, I. Hernando-Gil, A. Collin, G. Harrison} vol. 29, no. 4, 2014[13]: It applies the OPF technique to evaluate which demand-responsive loads in a given distribution network provide the maximum "value" to the system, in terms of their ability to relieve upstream network constraints and provide ancillary services, such as operating reserve. Detailed, aggregate load models of each of the main load sectors are applied, and a timesequential OPF is used to determine the effective MVA reserve which could be provided at the GSP interface by each load type. The OPF analysis is carried out using a standard industry tool (PSS/E), and therefore can be readily be applied by network operators to determine which DSM loads, or combination of DSM loads, can provide the maximum benefit to the system in a range of operational scenarios.

\section{Methodology}

A number of practical decision problems in business fall into a category known as network flow problems. These problems share a common characteristic - they can be described or displayed in a graphical form known as a network. This modelling focuses the network flow problems as a transshipment problem. The following procedure has been followed in order to find out the best path for the optimal power flow considering supply and demand nodes.

\section{A. Data Acquisition}

The basic data about generated power, power flow, the load demand and supply of various load centers, area of conductor, conductor size chart, temperature value, resistance, length of line etc. for setting up the objective functions and constraints, were acquired from the system operation department and grid operation department of Nepal Electricity Authority (NEA)[2].

\section{B. Modeling}

The transmission system contains a total of 14 substations that have been connected to the various supply nodes and connected within themselves. The voltage level considered for all of the connections is $132 \mathrm{kV}$ and $66 \mathrm{kV}$. The different incomers for each substation have been considered along with the maximum current at each incomer. Also, the demand during dry and wet season has been calculated. The average demand has been taken for the peak load period in the evening. A simple set of rules, known as the Balance-ofFlow Rules, applies to formulate the constraints for minimum cost network flow problems. For minimum cost network, apply the balance of flow rule as follows:

Flow Problems Where:

At Each Node:

Total Supply $>$ Total Demand Inflow-Outflow $\geq$ Supply or Demand

Total Supply $<$ Total Demand Inflow-Outflow $\leq$ Supply or Demand

Total Supply $=$ Total Demand $\quad$ Inflow - Outflow $=$ Supply or Demand

Table 1: Balance of flow rule

The network diagram shows that there are altogether 13 generating stations and 14 grid substations of Kathmandu valley, which are interconnected through different transmission networks.

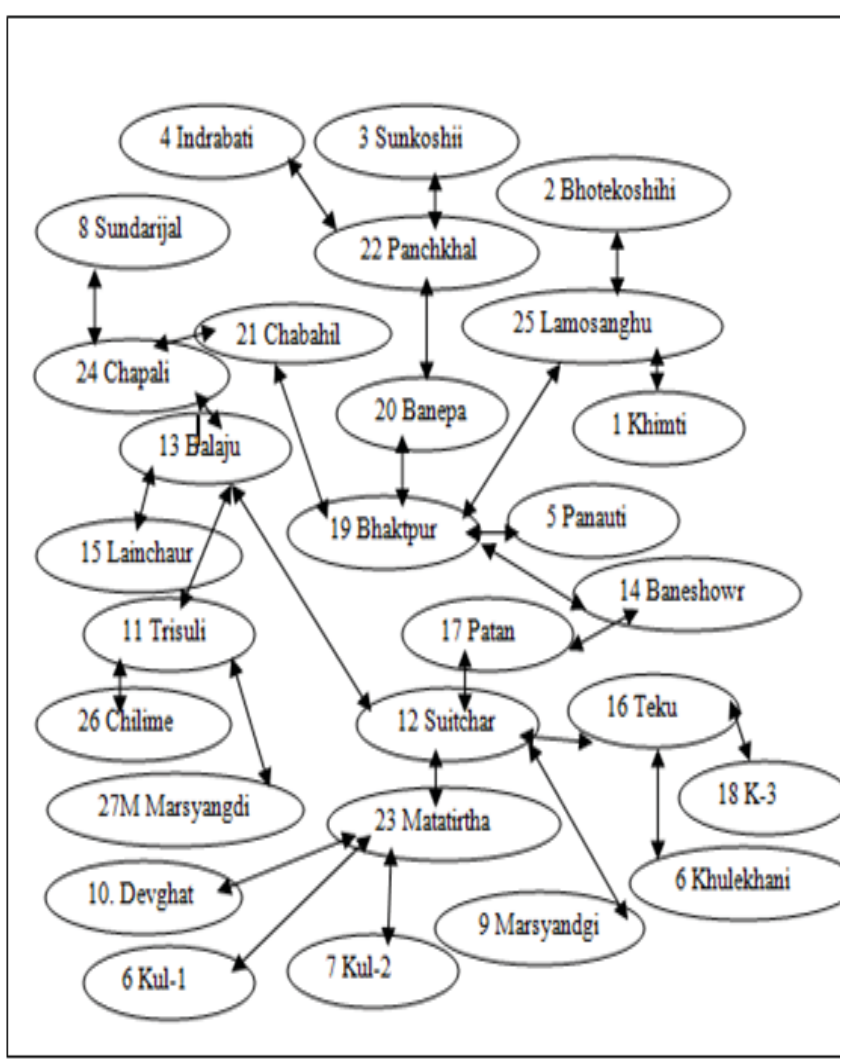

Fig1: Network diagram Demad and supply nodes

\section{Conversion to Transshipment Problem}

Generating stations (13-hydropower) are the supply nodes or sending nodes, and 14 substations are the demand nodes as well as transshipment 
nodes or receiving nodes. Substations nodes have the capability to consume power as well as transfer power to other substations. The positive number in the nodes signifies demand and negative number signifies supply nodes. The objective function is to minimize the line loss which is analogous to transportation cost. In such a way, it is possible to minimize line loss optimally.

\section{Setting up Decision Variables}

The goal in a network flow model is to determine how much power flows across each of the arcs or networks. For each arc in a network flow model, we define one decision variable as:

$X_{i j}=$ amount of power flowing from node $i$ to node $\mathrm{j}$ of power that in a network flow problem usually incurs some loss of power.

\section{Setting up an Objective Function}

The objective is to minimize the total loss that might be in the form of cost, distance or penalty factor. Loss minimization in each branch or lines is proportional to power flow and the line resistance. This is also called a minimum cost of the network flow problem.

$\mathrm{X}_{\mathrm{ij}}=$ amount of power flowing from node $\mathrm{i}$ to node j (MW)

Minimize: Power loss $\left(L_{i j}\right)=\sum\left[\frac{X_{i j} * 1000}{1.732 * V_{i j} * p . f}\right]^{2} * R_{i j}$

$\mathrm{L}_{\mathrm{ij}}=$ loss of power flowing from node $\mathrm{i}$ to node $\mathrm{j}$

$\mathrm{V}_{\mathrm{ij}}=$ voltage level of node $\mathrm{i}$ to node $\mathrm{j}(\mathrm{KV})$

$\mathrm{R}_{\mathrm{ij}}=$ Resistance of node $\mathrm{i}$ to node $\mathrm{j}$

p.f. $=$ power factor

\section{Setting up Constraints}

The network considered here is a dynamic network which is dependent upon numerous constraints such as thermal limit, resistance value, power flow, current; voltage, minimum demand availability of each load center etc., which are applied in the network. The number of nodes determines the number of constraints. Here, one constraint is applied for each node. A simple set of rules, known as the Balance-of-Flow Rules (Table2) is applied to formulate the constraints for the following minimum cost network flow.
Net flow $\leq$ Supply/Demand

Substation Demand $\leq$ Load Constraints

Total Demand with Load = Total Supply

Current across nodes $\leq$ Current limit of nodes

\section{Extracting the solutions}

The distance between the nodes and the corresponding transmission line resistances are assigned with specifying demand and supply capacities. The network flow problem is formulated according to the data available, constraints and objective function and solved in a spreadsheet. The designed flow problem is solved in order to find the optimal path in the following different scenarios.
i) Wet season (Nepal Power Only)
ii) Dry season (Nepal Power Only)
iii) Wet season (With India and Power)
iv) Dry season (With India Power)

\section{Spreadsheets Results}

\section{A. Wet Season (Nepal Power Only)}

The peak load of Kathmandu is at 275.20 MW during the wet season[2].

The following table summarizes the result.

\begin{tabular}{|l|l|}
\hline Total Line Loss In Mw & 6.6588 \\
\hline Total Supply & 281.86 \\
\hline Loss \% & $2.36 \%$ \\
\hline Total Demand & 275.20 \\
\hline Demand Met & 275.20 \\
\hline Total Demand with Loss & 281.86 \\
\hline \% of Demand Met & $100.00 \%$ \\
\hline Power Delivered by Kulekhani (MW) & 38.16 \\
\hline
\end{tabular}

Table 2: Result after solving the model at the wet season

\section{B. Dry Season (Nepal Power Only)}

In the dry season, the peak load of Kathmandu is at $315.60 \mathrm{MW}$. The total supply during the dry season is about $214.84 \mathrm{MW}[2]$.

The following table summarizes the result. 


\begin{tabular}{|l|l|}
\hline Total Line Loss In Mw & 3.3907 \\
\hline Total Supply & 214.84 \\
\hline Loss \% & $1.58 \%$ \\
\hline Total Demand & 315.60 \\
\hline Demand Met & 211.45 \\
\hline Total Demand With Loss & 214.84 \\
\hline \% of Demand Met & $67.00 \%$ \\
\hline Evening Load Shedding (MW) & 104.15 \\
\hline
\end{tabular}

Table 3: Result obtained from spreadsheet modeling at dry season

\section{Wet Season (With power import from India)}

Due to the acute power shortage and a huge gap between supply and demand, the country severely suffered from load shedding. To solve the problem of load shedding, Nepal has been importing power from India. Nepal has been importing up to 450 MW from India from various transmission line networks.

The following table summarizes the result.

\begin{tabular}{|l|l|}
\hline Total Line Loss (MW) & 6.1518 \\
\hline Total Supply & 281.35 \\
\hline Loss \% & $2.19 \%$ \\
\hline Total Demand & 275.20 \\
\hline Demand Met & 275.20 \\
\hline Total Demand with Loss & 281.35 \\
\hline Total Import From India & 12.35 \\
\hline \% of Load Shared from India & $4.49 \%$ \\
\hline Power Delivered by Kulekhani (MW) & 25.30 \\
\hline
\end{tabular}

Table 4: Result obtained after solving the model at the wet season

\section{Dry Season (With power import from India)}

The power shortage during the dry season is severe. The power import from India during dry season holds the key to meet the demand. Kathmandu has been free from load shedding for over a year, partly with the help of imported power from India. The runoff river power plants are operated in full capacity whereas the power imported from India and the power generated from Kulekhani have been taken to minimize the total loss.

The following table summarizes the result.

\begin{tabular}{|l|l|}
\hline Total Line Loss (MW) & 5.7030 \\
\hline Total Supply & 321.30 \\
\hline Loss \% & $1.77 \%$ \\
\hline Total Demand & 315.60 \\
\hline Demand Met & 315.60 \\
\hline Total Demand with Loss & 321.30 \\
\hline Total Import From India & 114.61 \\
\hline \% of Load Shared from India & $36.31 \%$ \\
\hline Power Delivered by Kulekhani (MW) & 63.85 \\
\hline
\end{tabular}

Table 5: results obtained after solving the model using the spreadsheet

During the wet season, the total demand for the Kathmandu at peak load condition cannot be met with the power generation from Run Off River power plants only. The only storage plant of Nepal, Kulekhani (38.16 MW) has to be used in the wet season to meet the peak demand. During the dry season, the total demand of Kathmandu at peak load condition cannot be met with the power generation from Nepal along with the use of Kulekhani in full capacity. The evening load shedding at the peak time would be 104.15 MW. The power imported from India is also used to meet the unmet demand during the wet season. For optimum performance and to minimize the loss, 25.3 MW of power has to be generated by Kulekhani whereas $12.35 \mathrm{MW}$ of imported power is to be used. The power imported from India is used to meet the unmet demand during the dry season. For optimum performance to minimize the loss, $63.85 \mathrm{MW}$ of power has to be generated by Kulekhani whereas 114.61 MW of imported power is to be used. The contribution of power import from India equals to $36.31 \%$ of total demand.

\section{Conclusion and Discussion}

This research has been done for the optimization of power flow with minimum losses that corresponds to minimum cost considering the various transmission line routes in Kathmandu valley. Power flow can be optimized for the dry as well as a wet season with power generation from Nepal and import from India. The spreadsheet modelling is taken as a transshipment flow network problem in order to identify the optimal path for optimal Power flow. During the dry season, the optimum new path is the flow as shown in network 
diagram bypassed power flow between Syuchatar to Matatirtha, Baneshwor to Patan, Baneshwor to Bhaktapur, Chabahil to Bhaktapur, Chabahil to Chpali. In this case, there is a minimum loss of $1.58 \%$ (about $3.39 \mathrm{MW}$ ) with a supply of $214.84 \mathrm{MW}$. During the wet season minimum loss is $2.36 \%$ (about $6.5 \mathrm{MW}$ ) off supply $281.86 \mathrm{MW}$. In the optimal operation, the following path is bypassed: Bhotekoshi to Lamosangu, Panauti to Bhaktapur, Syuchatar to Matatirtha, Balaju to syuchatar, Banepa to Pachkhal, and Chapali to Chabahil. The power imported from India is connected to Khimti and hetauda substation. Considering power from India to be $12.35 \mathrm{MW}$ during wet season, the minimal loss is about $2.19 \%$. During the dry season, $114.6 \mathrm{MW}$ power is imported from India accounts for $1.77 \%$ power loss. This analysis holds a key for planning, operation, economic scheduling and exchange of power between utilities. The selection of proper conductor and route helps to minimize power loss which could play a vital role in our country. The sole authority responsible for the design and operation of the transmission line, Nepal Electricity Authority (NEA), can use such type of optimization technique for the fast and reliable power system operation and control.

\section{Acknowledge}

The author greatly appreciates to Prof. Dr. Amrit Man Nakarmi and friends Manisha shahi, Sumesh Raut and Ramesh Adhikari for the kind co-operation during paper completion.

[1] H. M. Shrestha, "Cadastre of Hydropower Resources," Hydro Nepal, no. 15, pp. 87-89, 1991.

[2] Nepal Electricity Authority, "Annual Report Fiscal year 2017/18,” pp. 1-196, 2017.

[3] W. and E. C. Secretariat, "Government of Nepal Water and Energy Commission Secretariat Electricity Demand Forecast Report," no. January, 2017.

[4] J. J. Grainger and J. WUliam D. Stevenson, POWER SYSTEM ANALYSIS. 1994.
[5] C. T. Ragsdale, Spreadsheet Modeling and Decision Analysis, Fifth Edition. Virginia Polytech Institute and State University.

[6] Č. Zeljković and M. Gaćanović, "an Example of Using Microsoft Excel Solver for Power Network Calculations," pp. 2-6.

[7] R. Billinton and R. N. Allan, Reliability Evaluation of Power Systems, vol. 2nd Editio. 1984.

[8] L. Thurner et al., "Pandapower - An OpenSource Python Tool for Convenient Modeling, Analysis, and Optimization of Electric Power Systems," IEEE Trans. Power Syst., vol. 33, no. 6, pp. 6510-6521, 2018.

[9] A. Alidemaj, V. Komoni, G. Kabashi, and I. Krasniqi, "Control Active and Reactive Power Flow with UPFC connected in Transmission Line," 8th Mediterr. Conf. Power Gener. Transm. Distrib. Energy Convers. (MEDPOWER 2012), pp. 31-31, 2012.

[10] J. Schito, Modeling and optimizing transmission lines with GIS and Multi-Criteria Decision Analysis, vol. 59. 2017.

[11] Z. Li, J. Yu, and Q. H. Wu, “Approximate Linear Power Flow Using Logarithmic Transform of Voltage Magnitudes with Reactive Power and Power Loss Consideration," IEEE Trans. Power Syst., vol. 8950, no. c, pp. 1-1, 2017.

[12] J. Ma, L. Yuan, Z. Zhao, and F. He, "Transmission Loss Optimization-Based Optimal Power Flow Strategy by Hierarchical Control for DC Microgrids," IEEE Trans. Power Electron., vol. 32, no. 3, pp. 1952-1963, 2017.

[13] B. Hayes, I. Hernando-Gil, A. Collin, G. Harrison, and S. Djokić, "Optimal power flow for maximizing network benefits from demand-side management," IEEE Trans. Power Syst., vol. 29, no. 4, pp. 1739-1747, 2014.

$$
* * *
$$

